\title{
Multi-Dimensional Modeling of the A erodynamic and Combustion in Diesel Engines
}

\author{
A. Taklanti ${ }^{*}$ and B. Delhaye ${ }^{1 * *}$ \\ 1* PSA Peugeot Citroën, Direction des Techniques et A chats, 92250 La G arenne-Colombes - France \\ 1** PSA, Direction de la Recherche et de I'Innovation automobile, 78140 Vélizy-Villacoublay - France \\ e-mail: delhaye@calvacom.fr
}

\begin{abstract}
Résumé - Modélisation multidimensionnelle de l'aérodynamique et de la combustion dans les moteurs Diesel - Dans cet article, on présente un panorama des applications de la mécanique des fluides numérique et de la simulation de la combustion pour le développement des groupes motopropulseurs, ainsi que les méthodologies que nous avons conçues au sein du groupe PSA pour intégrer la simulation numérique dans ce processus de développement. Nous illustrons cette démarche par des exemples d'applications issues du développement des moteurs HDI injection directe common rail de PSA.
\end{abstract}

Mots-clés : modélisation, aérodynamique, combustion, Diesel, common rail.

\begin{abstract}
Multi-Dimensional Modeling of the Aerodynamic and Combustion in Diesel Engines - The purpose of this paper is to present an overview of Computational Fluid Dynamics (CFD) and combustion simulation applications to automotive power train development, and the methodologies we developed at PSA to integrate numerical simulation into the development process. We illustrate these methodologies with some applications concerning the development of PSA HDI engines.

Keywords: modeling, aerodynamic, combustion, Diesel, common rail.
\end{abstract}

\section{IN TRO DUCTIO N}

In the last decade, the automotive engine technology has been improved considerably, and many new concepts have been introduced, like Diesel and gasoline direct injection engines. The performance of engines and the driving pleasure have been improved, and the consumption and the emissions have been reduced drastically. At the same time, the development time has been shortened and the development costs have been cut off. To deal with this situation, Computational Analysis Engineering (CAE) in general, and CFD and combustion simulation in particular, are playing a more and more important role in the vehicle and power train development process.

In this paper, we will present a status of CFD and combustion simulation application to power train development. We will illustrate these applications with some examples issued from the development of PSA HDI common rail direct injection engines:

- intake manifold optimisation;

- in-cylinder aerodynamic;

- combustion modeling.

\section{STATUS OF CFD AND COMBUSTION SIMULATION}

CFD applied to automotive engines and power train components present many difficulties:

- complexity of the physics: turbulence, reactive flows, and multi-phase flows;

- complexity of the numeric: steady and unsteady flows, multi-scale and multi-physic;

- complexity of the geometry: complex geometry shape, moving walls.

\subsection{Physical Models}

The physical models proposed today in the CFD codes from academic institute or software developers are not perfect:

- For phenomena like turbulence and boundary layer, advanced and sophisticated models are available or under development in research institutes (DNS, LES, RSM, nonlinear $\kappa, \varepsilon$, etc.). However, the use of these models for industrial application is not practical today. They need a huge number of mesh cells and a huge computation time. 
They often show problems of stability and convergence. So the major CFD and combustion applications are using the standard $\kappa, \varepsilon$ turbulence model with log law wall functions.

- For phenomena like spray, fuel ignition, fuel combustion and pollutant formation, our knowledge of the physics is very limited, and the available numerical models can't predict perfectly what happens in a real engine with a standard fuel you can buy at service station.

\subsection{CFD Integration into Development Process}

We consider that CFD and Combustion simulation are tools, as well as experiments, capable to help design and also test engineers to:

- analyse and understand physical phenomena occurring in the power train components;

- improve and optimise the components design;

- evaluate, compare and choose between different solutions.

So, numerical simulation is a complementary tool to experiments that allow the investigation of a large number of solutions in a relatively short time and a reduced cost.

At PSA we developed CFD and combustion simulation methodologies to study and analyse flow field, heat transfer and combustion within the power train components: intake system, filters, manifolds, ports, in-cylinder and combustion chamber, exhaust system, engine water jacket cooling.

First step of these methodologies consists in:

- Validate the physical models and define the usable domain and the limit of the models.

- Validate the numerical models and define rules for grid size and refinement, grid quality. The goal is to try reach mesh independence and to ensure reproducibility of the results.

- Validate the simulation process: interface with CAD system to get and clean up geometry, mesh generation, pre and post-processing.

- Validate the exploitation of results and define correct and pertinent evaluation criteria to be extracted from computation.

Another important point is the turn around time to perform numerical simulation. It has to fit into the frame of the development process. So, the link to CAD system and reduction of mesh generation time are of great importance and interest. For this purpose, we are investigating the new approach using automatic mesh generation (Fire Automesh and Fame modules, hybrid and mixed meshes) and Cat/Fire, the integrated version of Fire into the Catia Cad system.

All the validation and integration process is developed with the collaboration of the design engineers, the test engineers, CAD system specialists and computer system specialists.

\section{INTAKE MAN IFO LD OPTIMISATIO N}

\subsection{Intake Manifold Steady State Flow}

CFD is widely used to optimise the pressure drop, flow distribution and flow structure in power train ducts and manifolds. We perform with Fire code simple steady state computations with mass flow or total pressure condition at inlet, and pressure condition at outlet. Figure 1a shows the mesh of an intake manifold of 16 valves direct injection Diesel engine. Figure 1b shows an example of velocity vectors on a cutting plane. The analysis of the pressure drop and the flow structure help and allow the designers to modify the geometry, improve the pressure drop, reduce the dispersion of cylinders filling and predict the generated swirl through the different outlet ducts. Figure $2 b$ shows the mesh of a modified manifold.

a) Computational mesh

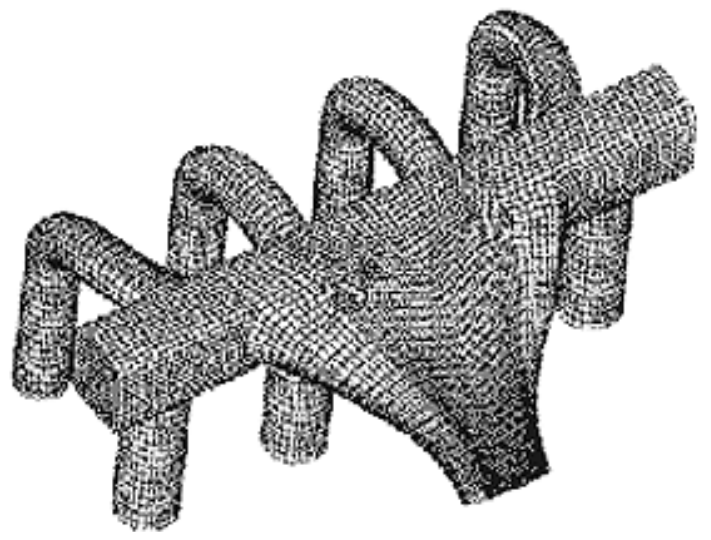

b) Velocity vectors. Cylinder 1 is open

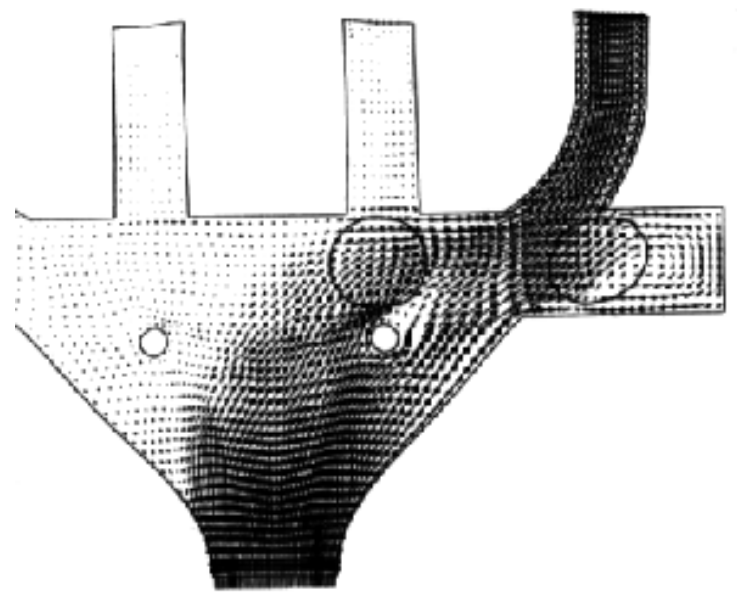

Figure 1

Intake manifold steady state flow. 
a) 1D gas dynamics layout

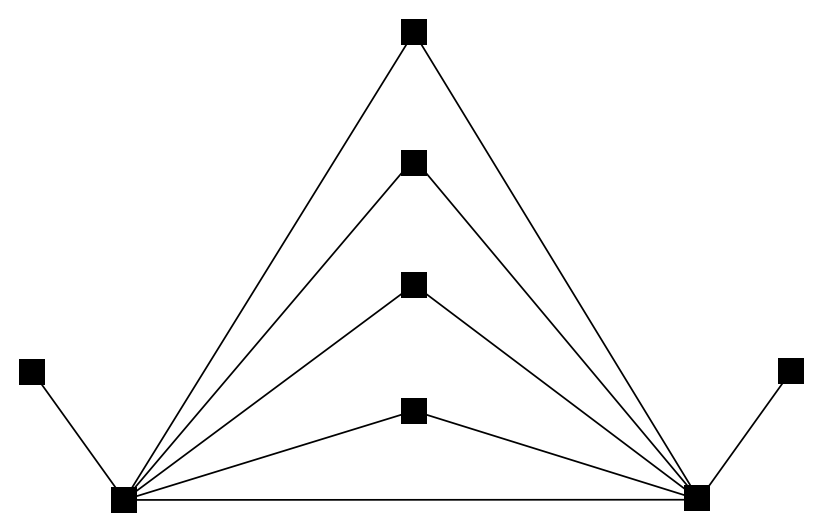

b) Intake manifold mesh

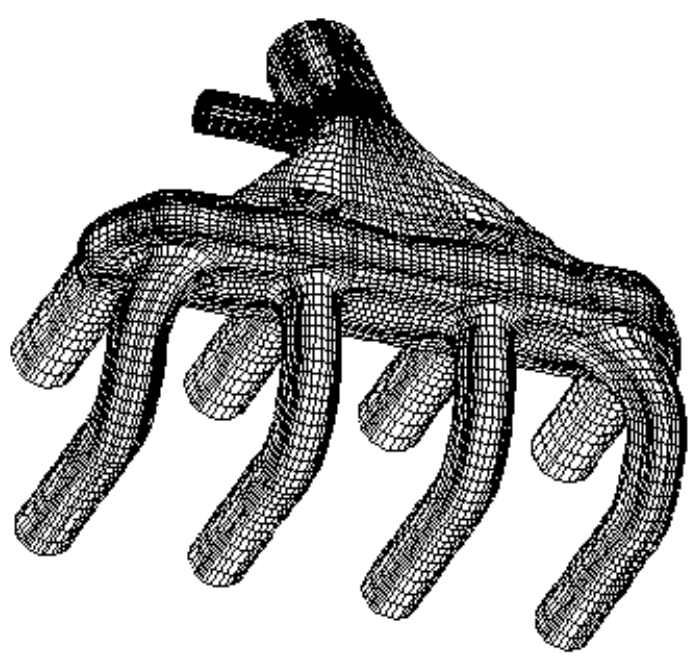

c) Total mass flow

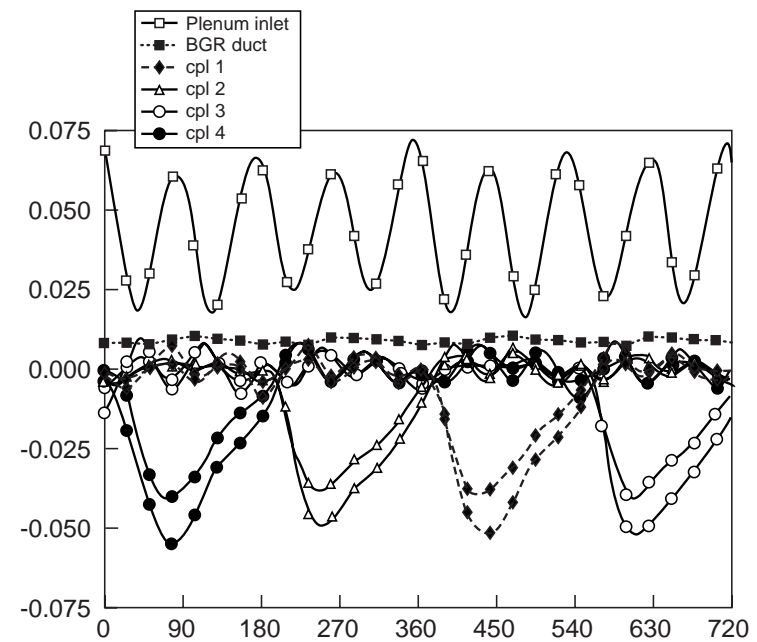

d) EGR mass flow

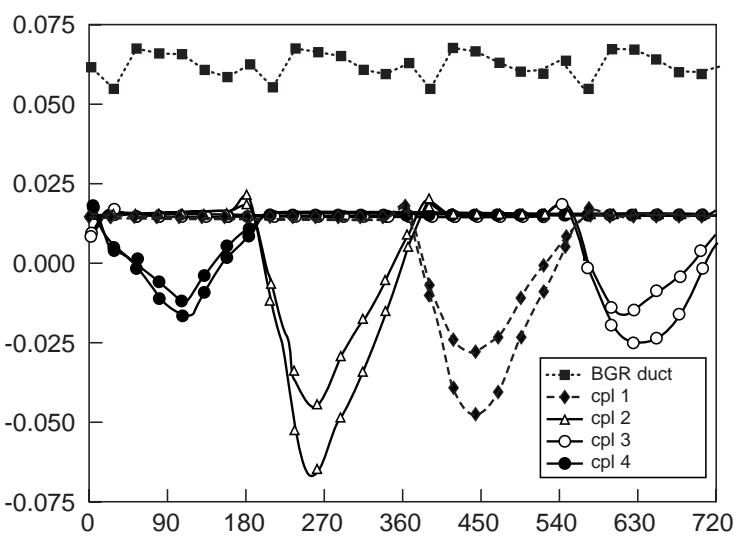

e) Velocity field

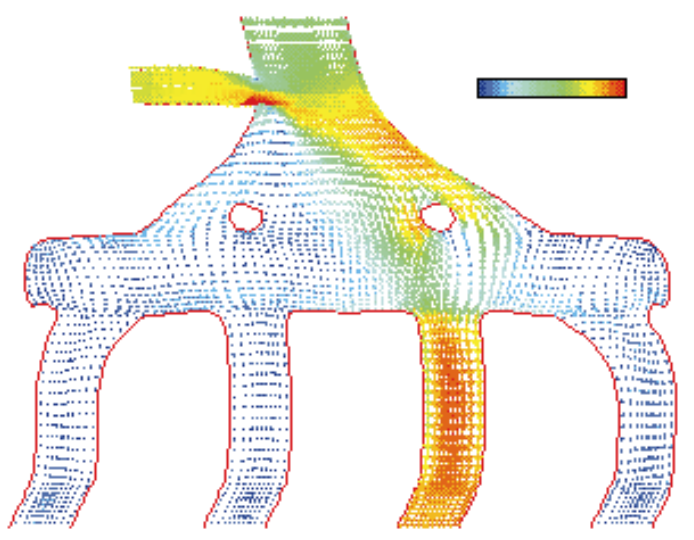

f) EGR distribution

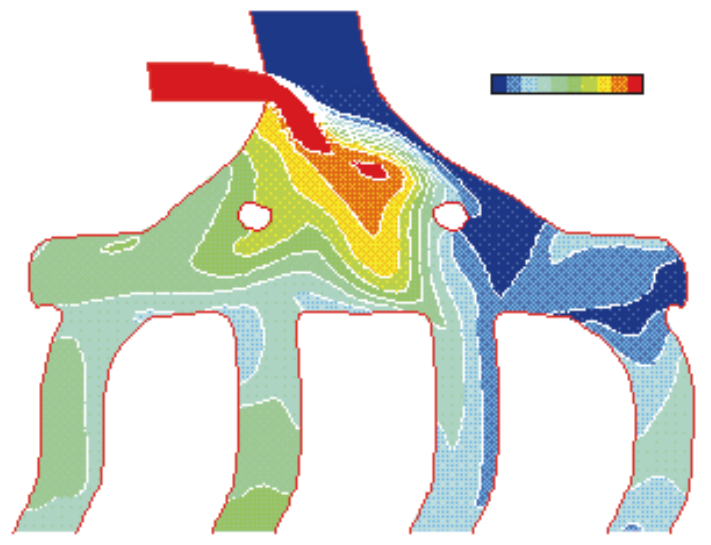

Figure 2

EGR distribution in Diesel engine. 


\subsection{EGR Distribution in Diesel Engine}

To analyse the Exhaust Gas Recirculation (EGR) distribution in the cylinders, the steady state approach is not enough. It is necessary to take into account the unsteady pressure waves in the intake, in-cylinder and exhaust systems, and the mixing between fresh and burned gas. For this purpose, we developed in collaboration with $A V L$, the coupling of an in house one-dimensional gas dynamic code called Respir, and the Fire code [1]. Figure 2a presents the 1D gas dynamic layout of a 16 valves direct injection engine. A 3D mesh shown in Figure $2 \mathrm{~b}$ replaces the intake manifold.

The computation is performed for an engine speed of $3000 \mathrm{tr} / \mathrm{min}$ full load. We need 5 to 6 engine cycles to reach a converged solution. The EGR is considered in the 3D computation as a passive scalar with the temperature and the density calculated by Respir. Figure 2c shows, for the last engine cycle, the evolution of the total mass flow in the plenum, and the total mass flow through the tangential and the helical ducts of each cylinder. The Figure $2 \mathrm{~d}$ shows the inlet EGR mass flow from EGR duct and the outlet EGR mass flow from each outlet duct. The distribution of total mass flow is quit homogeneous for the 4 cylinders, but the EGR fraction in cylinders 1 and 2 ducts is about two times higher than for cylinders 3 and 4 . Figure $2 \mathrm{e}$ and $2 \mathrm{f}$ present velocity vectors and EGR distribution in a cutting plane at degrees c.a. $=630$ when cylinder 3 is open. They show that the EGR flow is deviated by the incoming airflow, and the EGR is trapped in the left part of the manifold near cylinders 1 and 2 ducts. So, the position of the EGR duct and manifold junction has to be modified. With a steady state 3D computation, or a 1D gas dynamic computation, it is not possible to investigate such a problem.

\section{IN CYLIN DER FLOW}

To study and optimise the combustion chamber and the piston bowl of a direct injection diesel engine, we developed different methodologies:

- swirl compression in a simplified 2D-axisymmetric geometry;

- compression, injection and combustion of a simplified axisymmetric sector;

- 3D admission and compression in a complete engine.

\subsection{Swirl Evolution in Piston Bowl}

To optimise the piston bowl shape of direct injection engine, we developed a methodology to analyse the evolution during compression and expansion of an imposed swirl flow in the cylinder. We consider axisymmetric geometry, and we generate an automatic 2D mesh using the Fire Automesh module as it is shown in Figure 3a. We start computation at $\mathrm{BDC}$ and we calculate the compression and the expansion for different tr/min and different initial swirl numbers. a) $2 \mathrm{D}$ axisymmetric mesh

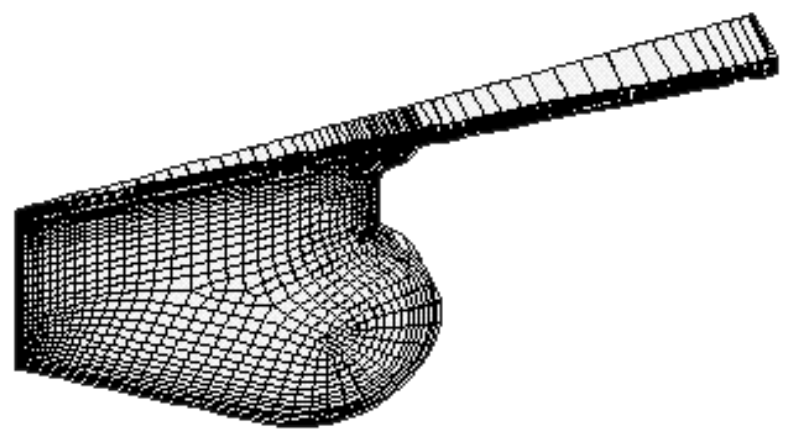

b) $3 \mathrm{D}$ sector axisymmetric mesh

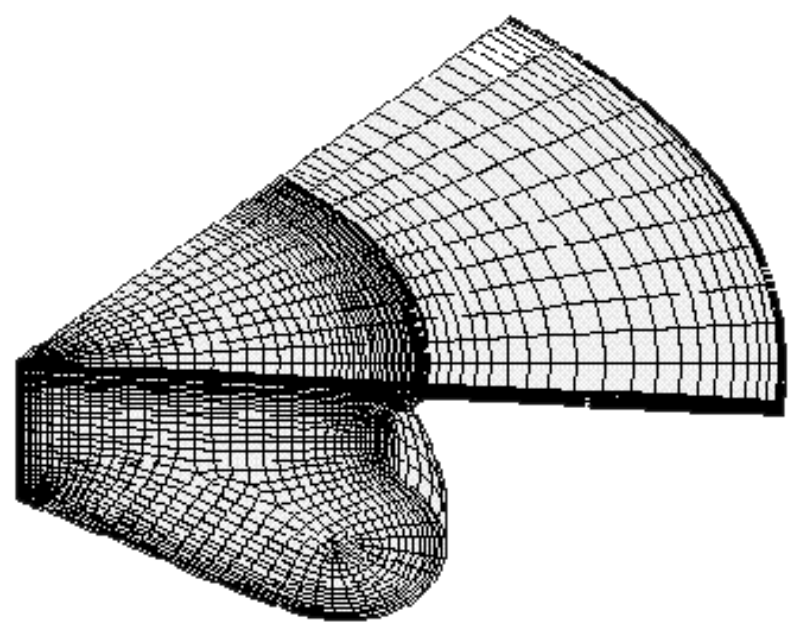

c) Piston bowl swirl evolution

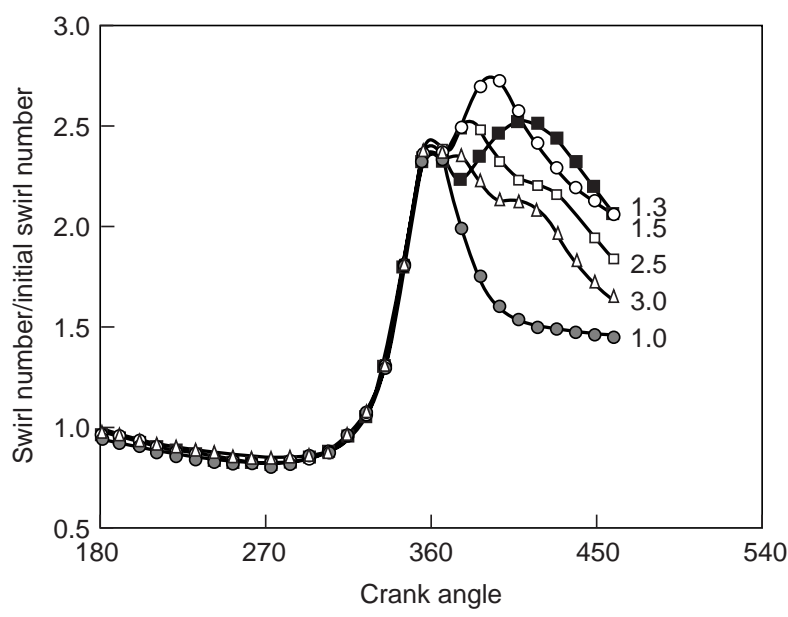

Figure 3

Swirl evolution in piston bowl of direct injection Diesel engine. 
Figure $3 \mathrm{c}$ shows the swirl number evolution in the bowl for different values of initial swirl number. So, we can investigate the conservation of swirl structure in the bowl after ATDC.

\subsection{Spray and Swirl Interaction}

With the same 2D automatic mesh, we can generate a 3D mesh for a sector as it is shown in Figure 3b. A computation with injection allows us to investigate the interaction between the aerodynamic and the spray in the piston bowl. Figure 4 shows the temperature field and the spray.

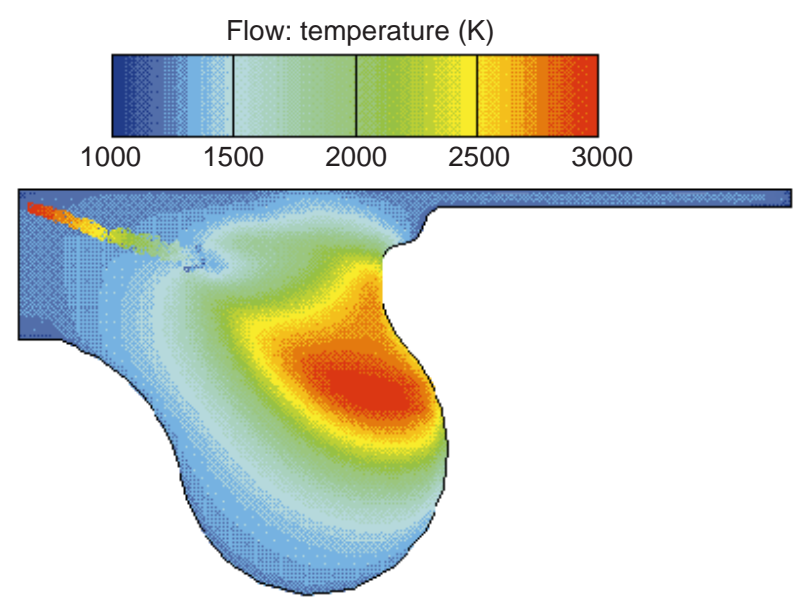

Figure 4

Spray and temperature field in the piston bowl.

\section{COMBUSTION MODELNG}

\subsection{Model Description}

The simulations in this part were accomplished using a modified version of the Kiva-II code, originally developed at Los Alamos National Laboratories [2] for engine flow simulations and widely used for internal combustion engine modeling and other applications. In the present calculations, the $\kappa-\varepsilon$ model uses wall function to bridge the viscous sublayer region. The submodels are briefly described here after. The spray model is the Wave-Fipa model [3, 4], a new model, which includes a primary, and a secondary, atomisation. The ignition model is based on the Shell ignition model modified by Zellat and Zeller [5]. The combustion model is the Magnussen model. The Zel'dovich mecanism is used to predict NO and the soot formation model is the Morel model [5]. These models were applied to simulate singleinjection combustion, first in a bomb in order to validate the spray modeling with the new model and then in a PSA Diesel engine under a wide range of operating conditions.

\subsection{Engine Geometry}

The engine specifications are summarised in Table 1. This engine is a two-valves Diesel engine. Only the intake-side valve and port are modeled. The computational mesh of this engine is illustrated in Figure 5. It contains at BDC a maximum of 100000 cells.

TABLE 1

Engine specifications

\begin{tabular}{l|l}
\hline Parameter & Engine \\
\hline Bore & $85 \mathrm{~mm}$ \\
\hline Stroke & $88 \mathrm{~mm}$ \\
\hline Connecting rod length & $145 \mathrm{~mm}$ \\
\hline Compression ratio & 19 \\
\hline $\mathrm{Nb}$ of nozzle orifice & 5 \\
\hline Diameter of orifice & $0.20 \mathrm{~mm}$ \\
\hline Intake valve opening & $-397^{\circ}$ BTDC \\
\hline Intake valve closing & $-153^{\circ}$ BTDC \\
\hline
\end{tabular}

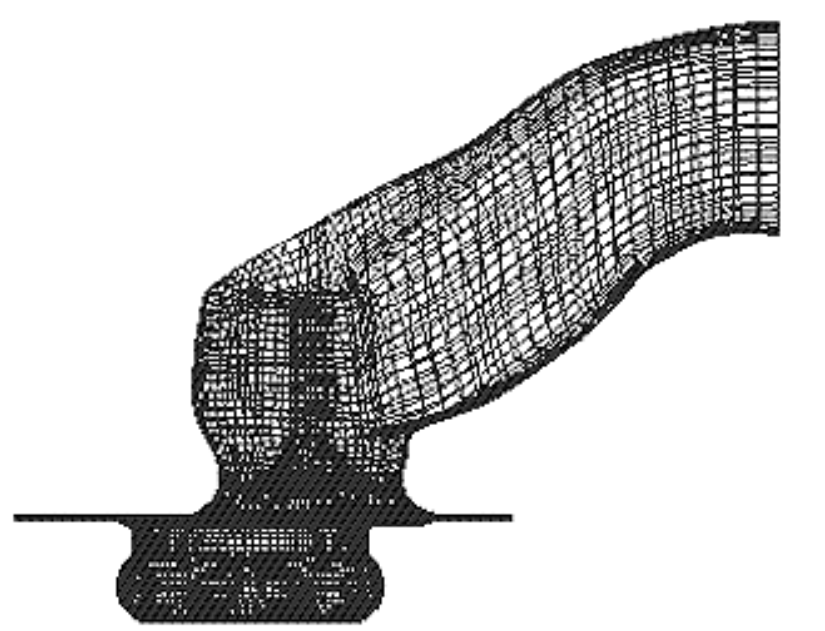

Figure 5

Computational mesh.

Boundary and initial conditions were created using a onedimensional engine simulation model. The outputs for Kiva-II are, for the initial conditions, the temperature and pressure in the cylinder and in the manifold and, for the boundary conditions, the evolution of the temperature, density and mass flow in the manifold. The wall temperature was assumed to be constant in space and time during all the calculation.

The in-cylinder homogeneous air-fuel mixture is initially quiescent. The turbulent kinetic energy is equal to $15 \%$ of the kinetic energy of the piston. Calculations start at TDC in the intake stroke. 


\subsection{Results and Discussion}

A total of five different experimental cases in a firing engine were modeled and simulated as a test for the combustion modeling approach. The engine operating conditions are summarised in Table 2. The cylinder pressure was measured for all the five cases. These results were used to validate the models. Note that a consistent time reference is used throughout this paper with $-360^{\circ}$ being TDC overlap and $0^{\circ}$ TDC firing.

The mean pressure is plotted in Figure 6, 7 and 8. Figure 6 shows the effects of a variation of injection timing, Figure 7 shows the effects of a variation of engine speed and Figure 8 shows the effect of a variation of load. In all the five cases the results of the Kiva-II simulations predict the pressure trace fairly well. Figure 9 shows the numerical results concerning $\mathrm{NO}_{\mathrm{x}}$ with the new modeling approach (using Wave-Fipa instead of Fipa) [6]; agreement is rather good. For the soot prediction results are plotted in Figure 10, and the disagreement between numerical results and experimental data is almost the same.

TABLE 2

Test cases and operating conditions

\begin{tabular}{c|c|c|c}
\hline Case & $\begin{array}{c}\text { Speed } \\
(\mathrm{tr} / \mathrm{min})\end{array}$ & $\begin{array}{c}\text { Load } \\
(\mathrm{mg} / \mathrm{cyl} .)\end{array}$ & $\begin{array}{c}\text { Injection timing } \\
\left({ }^{\circ} \mathrm{BTDC}\right)\end{array}$ \\
\hline $\mathrm{A}$ & 2250 & 15.50 & 8.9 \\
\hline $\mathrm{B}$ & 2250 & 15.50 & 4.3 \\
\hline $\mathrm{C}$ & 2250 & 15.50 & 13.1 \\
\hline $\mathrm{D}$ & 3000 & 16.10 & 12 \\
\hline E & 2250 & 36.50 & 13.1 \\
\hline
\end{tabular}

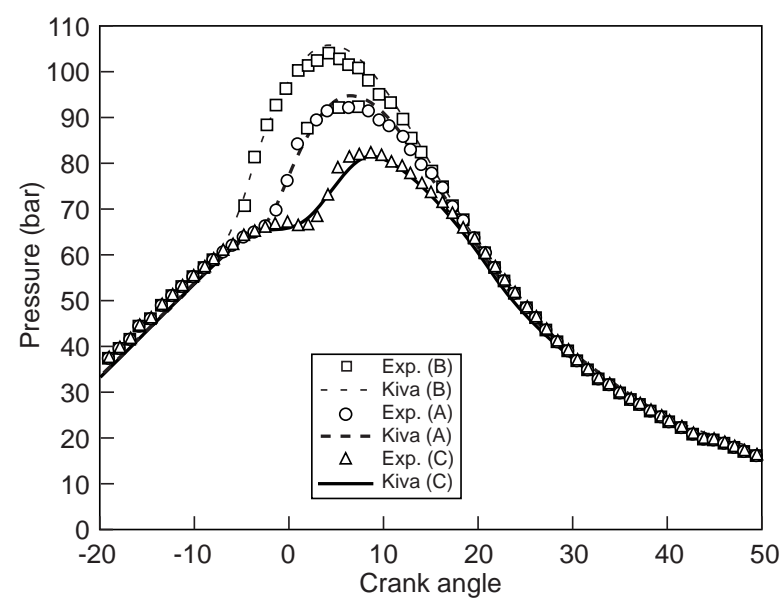

Figure 6

Effect of injection timing on cylinder mean pressure.

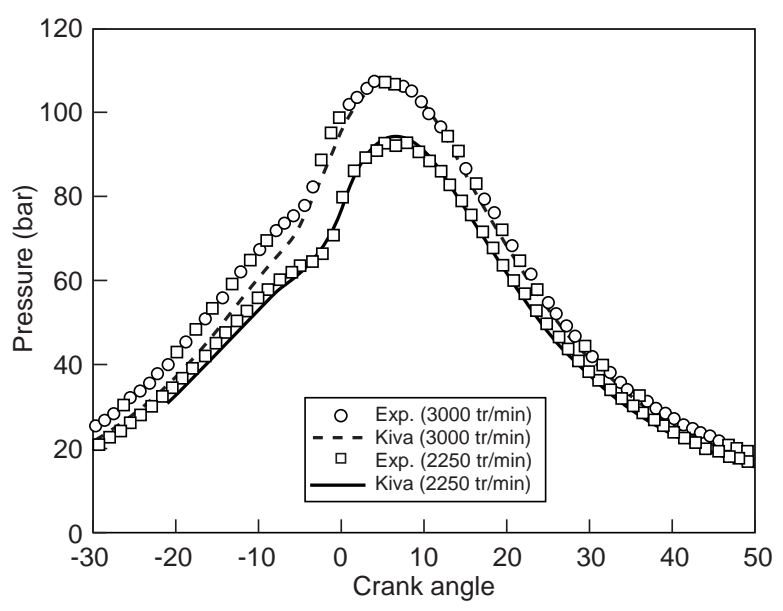

Figure 7

Effect of engine speed on cylinder mean pressure.

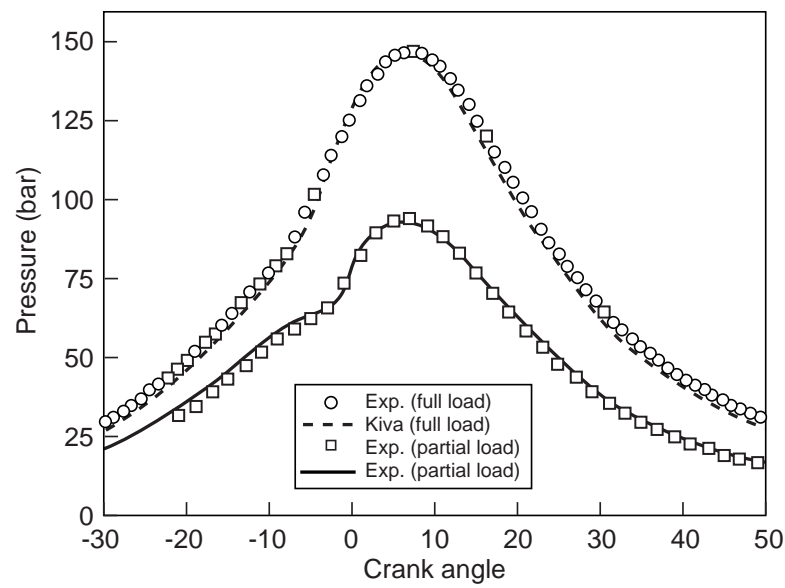

Figure 8

Effect of load on cylinder mean pressure.

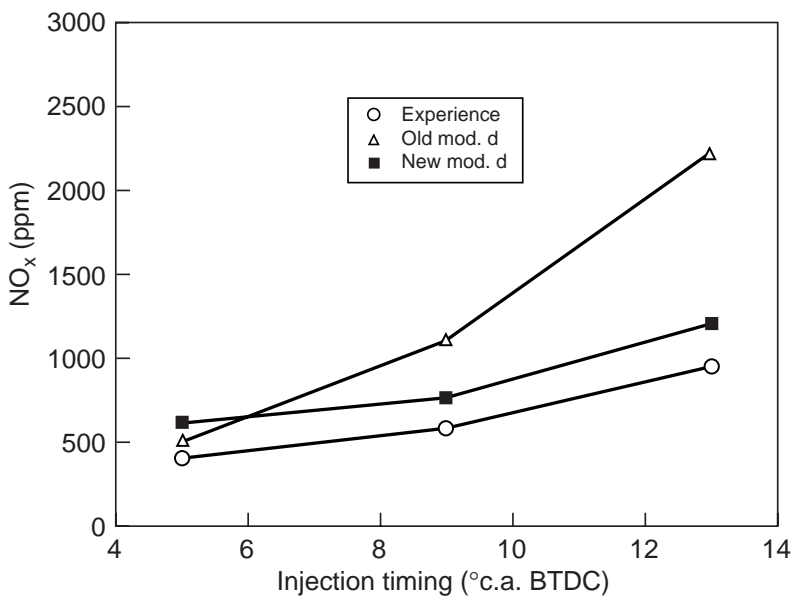

Figure 9

Evolution of $\mathrm{NO}_{\mathrm{x}}$ emission with injection timing. 


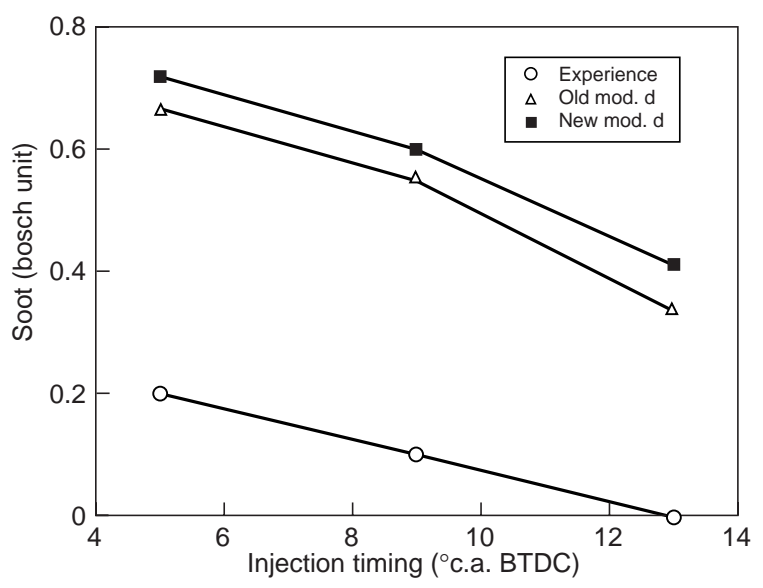

Figure 10

Evolution of soot emission with injection timing.

\section{CONCLUSION}

We presented here an overview of CFD and combustion applications to automotive power train development with several numerical tools, a 1D code and two different 3D codes (Fire and Kiva-II). The combustion simulation was validated by comparisons with experimental data concerning the temporal evolution of cylinder mean pressure and pollutants. Good agreement was obtained in all the cases except for soot formation.

\section{REFEREN CES}

1 Mouro, J. and Raulot, A. (1997) Coupling of a 1D Gasdynamics Code with Fire. 3rd International FIRE User Meeting.

2 Amsden, A.A., O'Rourke, P.J. and Butler, T.D. (1989) Kiva-II: A Computer Program for Chemically Reactive Flows with Spray. LA-11560-MS, Los Alamos National Laboratory, Los Alamos, NM.

3 Reitz, R.D. (1987) Modeling Atomisation Processes in HighPressure Vaporising Sprays. Atomisation \& Sprays, 3 309-337.

4 Étude GSM (1997) Développement d'un nouveau modèle de jet et validation. Rapport IFP, 43655.

5 Étude GSM (1994) Modélisation Diesel : évaluation de la combustion Diesel sur moteur à injection directe. Rapport IFP, 41499.

6 Habchi, C., Torres, A., Lambert, L., Moin-Ansari M. and Baritaud T. (1996) Modélisation de l'injection haute pression et validations. Rapport IFP, 43226.

Final manuscript received in March 1999 